\title{
Machinery Maintenance Viewpoint: One Approach to an Improved Rural Road Traffic Safety in Southwest Nigeria
}

\author{
${ }^{* 1}$ Hezekiah O. Adeyemi, ${ }^{2}$ Oluwaseun O. Martins, ${ }^{3}$ Olanike O. Ade-Ikuesan, \\ ${ }^{3}$ Olawale O. Olaluwoye
}

\author{
${ }^{l}$ Department of Mechanical Engineering, Olabisi Onabanjo University, Nigeria \\ ${ }^{2}$ Department of Mechatronics Engineering, Federal University Oye, Ekiti, Nigeria \\ ${ }^{3}$ Department of Electrical Electronics Engineering, Olabisi Onabanjo University, Ago-iwoye, Nigeria \\ *Email: adeyemi.hezekiah@oouagoiwoye.edu.ng
}

\begin{abstract}
Local Governments (LGs), the third tier of government in Nigeria, are expected to maintain infrastructure facilities at the grass root level but most rural communities in Southwest Nigeria are characterized by poorly maintained roads. This study assessed conditions of Moveable Rural Road Maintenance Equipment (MRRME) under LGs in Southwest Nigeria vis-a-vis the safety levels on the rural roads. The study measured, impacts of roads conditions on commercial drivers/riders (cdr) and, level of usage of MRRME for the roads. Questionnaires were used to measure: accident rates and impacts among $250 \mathrm{cdr}$ on 9 selected rural roads; Maintenance Performance Measures (MPM) of MRRME among 430 Senior Technical Officers (STOs) and Senior Finance Offices (SFOs) in 84 LG secretariats. The conditions of MRRME were carried out using observational method. More than $72 \%$ of cdr were involved in one crash or another and $89 \%$ of them attributed this to bad roads. Less than $26 \%$ of MRRME was functional with weak plans/tools put in place for correct maintenance program leading to a high level of MRRMEs' failures and total neglect. T-test $t$ $(428)=-5.146, p=0.421$ ) found that the opinions of STOs (poor ratings for MPM policy implementation) were not different from that of the SFO. There is the need for safety attitudinal change among cdr. LGs also need empowerment to ensure proper maintenance of MRRME and enhances their availability. These measures among other will reduce accidents death counts on Nigeria rural roads.
\end{abstract}

Index Terms- Rural, Road, Safety, Machinery, Maintenance, Nigeria

\section{INTRODUCTION}

Road traffic safety is a technique put in place at reducing the harm, resulting from crashes of road, to all categories of road users (motorist, cyclists, pedestrian e.t.c) using public roads. Road traffic injuries are ranked ninth globally among the leading causes of disability adjusted life years lost [1]. Worldwide, it is estimated that 1.2 million people are killed in road crashes each year and as many as 50 million are injured [2]. Road accidents occur as the result of one or more than one of human factor, vehicle factor and road/environment factors [3].

Most countries of the developing world are characterized by inadequate and poorly maintained road [4] and the majority of those injured in road traffic crashes are pedestrians, cyclists and motorized [5]. Motorcycle was however rated the most dangerous because there is no structure to protect the rider during a crash. Riders involved in road traffic crashes are likely to be seriously disadvantaged by the lack of available safety equipment such as seat belts, lower limb protectors and air bags [6].

However, according to Bryson [7], motorcycle and other mode of transportations crashes are preventable and the associated factors causing injuries are reducible if necessary laws and restrictive regulations are put in place with implemented educational programs on road safety. In Nigeria, the condition of rural areas is pathetic since they are highly deprived of infrastructural facilities, especially when compared to the urban areas [8] and the poor state of 
the road forms a major causal factor for many rural road crashes and insecurity. Many rural roads had become huge slaughter slabs as they had been denied all forms of maintenance [9]. According to Okigbo [10] most of the road networks in Nigeria are deplorable and could not be said to be in good condition because governments at all levels have fallen short of international benchmarks interms of proper road infrastructure maintenance [11]. The financing of the maintenance, rehabilitation and conservation of the roads network had always been left to the government at the Local Government (LG) levels who, because of their lack of maintenance culture, do not release funds at the appropriate time. For this and other reasons, Aderamo and Magaji [12] explained that the LG could not shoulder the financial responsibility of maintaining rural roads. Therefore the road network was left to deteriorate to the extent that majority of them became impassable [13]. The poor conditions of the road usually lead to incessant robberies and it remains a major transportation problems faced by rural residents. Abdulkadir [14] suggested policy options include provision of adequate funds for road construction and maintenance-oriented approach which include, among others, all supports to keep road maintenance equipment functioning.

Maintenance is the combination of all technical and administrative actions, including supervision, intended to retain an item in, or restore it to, a state in which it can perform a required function [15]. Maintenance can be corrective (the machinery run until it fails) or preventive (to avoid breakdown by anticipating failure or wear and making a timely examination, replacement or adjustment). Preventive maintenance is usually considered more expensive than the corrective but it has been reported as the best [16]. It includes daily maintenance, minor repairs, and major system replacement. Movable rural road maintenance equipment (MRRME) required proper maintenance to work efficiently and properly to maintain roads at the grass root level. There are many MRRME required for road maintenance. These include among others, motor grader, compactor, road paver, asphalt concrete plant, trucks, tipper, mixers and concrete placers. Deferring maintenance of these equipment when it is required may save funds in the short term, but the effects of deferring begin to impact upon the plant utilization. At this stage, it is often too late or expensive to correct faults because the costs of playing 'catch up' maintenance will be much more had it been performed properly earlier [17]. One major benefit of preventive maintenance of machinery is to prolong their life. Iwarere and Lawal [16] identified adequate training programmes as a major solution to proper maintenance of public facilities.

Maintenance workers need training on what to look for and how to assess equipment conditions whether they are critical, could damage other components, or simply require routine repair. Such training should be a continuous program, not a one-time event and should be targeted at an employee's individual needs for improvement of competence and productivity [18].

According to Adedokun [19], infrastructural development is the bedrock of any development in the modern world. However, without a strong maintenance culture, efforts at infrastructural development will not be fruitful. As reported by Abdulkareem and Adeoti [20], maintenance of infrastructural machinery in Nigeria LGs system is inadequately handled. Whereas the LGs are expected to enhance achievement of infrastructural services in provision and maintenance of facilities, but they are rather known to be symbols of non-performance, slow administrative processes and lack of innovations having a very little visible impact on the lives of the rural population [21].

This study attempted to assess the conditions of MRRME under the Local Government management in Southwest Nigeria vis-a-vis the safety levels on the rural roads. The objectives are to measure the; impacts of the roads conditions on the commercial drivers/riders (cdr) and, level of availability of MRRME for the rural road rehabilitations. 


\section{MATERIALS AND METHODS}

\subsection{Study domain and period}

This study involved an extensive cross sectional studies design and conducted during the period of 2015-2016. It included studies to examine the MRRME and, surveys with the use of questionnaires to assess MRRME adopted in 84 LGs of Western Nigeria. Within the same study domain, nine (9) rural roads were selected for road traffic safety assessment.

\subsection{Rural roads' traffic safety survey}

A set of questionnaire to measure safety on the roads was administered on 125 commercial rural road users (136 motorcycle riders and 89 motor vehicle drivers) in the 9 selected roads. Information relating to whether they were involved in any crash on the road, causes and type of the accident were asked to be provided with their opinions on the possible solution to improving the traffic safety on the roads. Subjects were asked to rate safety approach of LGs on how well they perform with reference to rural road safety for all users using scores scale of 0 to $5(0=$ not perform, $1=$ poorly performed, $2-3=$ performance available but not enough, 4 $5=$ performance very adequate).

\subsection{Moveable rural road maintenance equipment direct observational method}

Observations and physical assessment of motor grader, lorry, pay loader, boiler, low loader and monitoring vehicles, for road maintenance works were carried out. The maintenance officers in charge of the equipment were asked to rate conditions of the road equipment as either functional or non-functional following the techniques highlighted by Alexander et al. [22].

\subsection{Assessment of Maintenance Performance Measures (MPM)}

A modified structured survey which followed a set of standardized questionnaire on MPM and the quidlines as stated by Steven [23] and Jody [24] was administered to 185 Senior Technical Officers (STO) and 245 Senior Finance Officers (SFO) in the 84 LGs. The MPM elements included; (i) Long and short-term planning for maintenance (ii) structuring a framework for operating a maintenance program and (iii) advancing the competence of maintenance workers and equipment managers.

Both the STO and SFO were asked to rate the road equipment maintenance policy implementation of their employers on the three MPM elements with numeric scores $(0=$ not perform, 1 = poorly performed, $2-3=$ performance available but not enough, $4-5=$ performance very adequate). According to Numrah [25], MPM is a regular measurement of outcomes and results, which generates reliable data on the effectiveness and efficiency of a program. Evaluating performance of maintenance among others involves analyzing data on its impact and efficiency [26].

Data collection was conducted at LG secretariats and offices during the working period and at a time agreed upon by the subjects. Consents of all potential participants were received orally, after they were informed that their participations in the study were voluntarily. The purpose of the study and the confidentiality of the information provided were emphasized.

\subsection{Statistic test}

The independent sample t-test was used to determine the difference between the MPM implementation mean scores as rated by STO and the SFO at $p<0.05$. The independent samples t-test evaluates the difference between the means of two independent groups whether the means are significantly different from each other or not. The independent sample t-test is probably the single most widely used test in statistics [27]. 


\section{RESULTS AND DİSCUSSIOON}

\subsection{Rural roads traffic safety survey}

3.1.1 Description of subjects' demographic information, responses and questionnaire return rate

Figure 1 is about the demographic features of the population of respondents, their age distributions, education level and other aspects of the subjects' population which related to their work. The respondents were categorized under two-the commercial motor vehicle drivers and the motorcycle riders. As described in the Figure, at least $79.7 \%$ of all the subjects have spent not less than two (2) years on their current job, $75 \%$ plied the road daily with $38.2 \%$ holding at least a diploma as the highest level of education/training completed. In total, two hundred and twenty five (90\%) (Including 136 motorcycle riders and 89 motor vehicle drivers) completed the survey

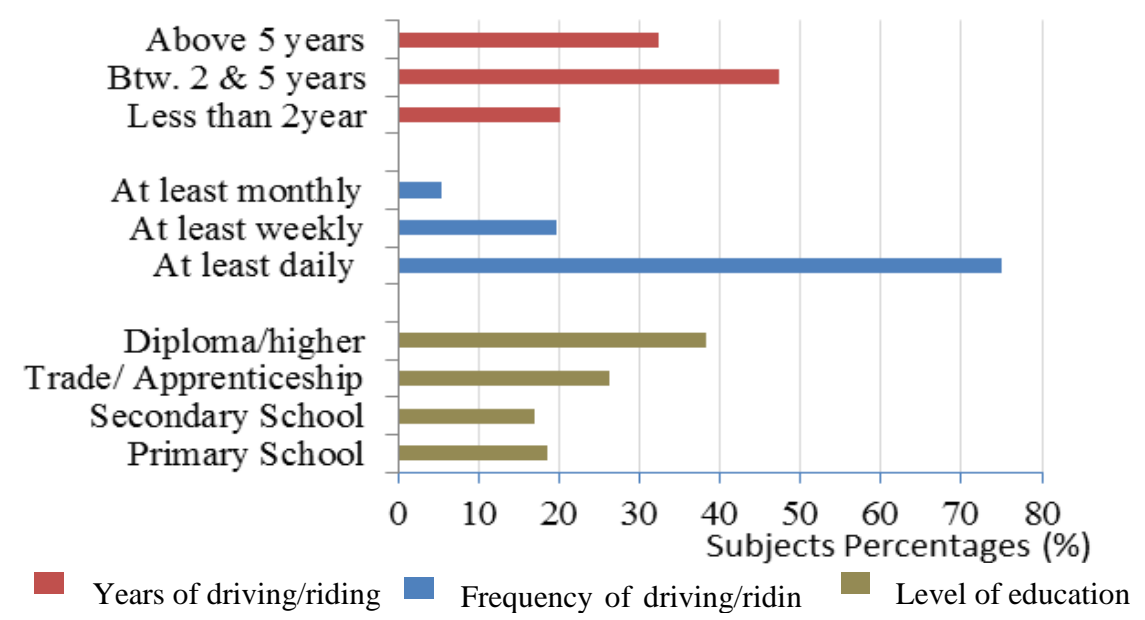

Figure 1: Demographic information of 225 drivers/riders in 9 selected rural roads

\subsubsection{Drivers/riders' reported experienced rural road crashes types}

Figure 2 is a pie chart divided into slices to illustrate numerical proportion of commercial drivers/riders who reported one type of rural road crashes or another. Among the studied subjects, $67 \%$ reported that the crashes involved lone motor cycle, $42 \%$ reported motor cycle-motorcycle, $25 \%$ had motor cycle-pedestrian while $16 \%$ and $12 \%$ were motor cyclefixed object and motor cycle-motor-motor vehicle category.

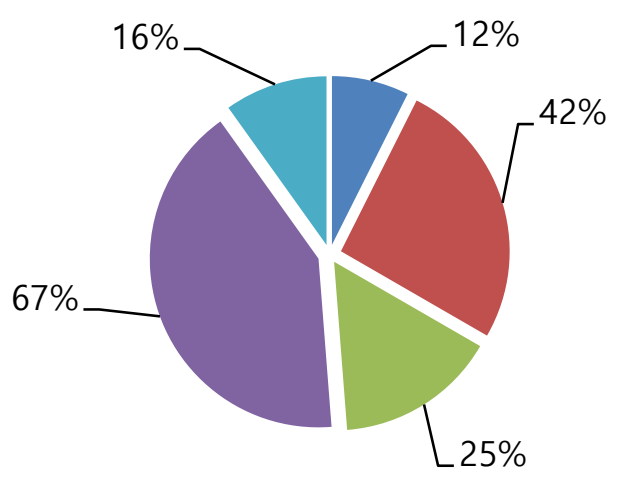

Motor cycle-motor vehicle

- Motor cycle-motor cycle

Motor cycle-pedestrian

Lone motor cycle

Figure 2: Commercial drivers/riders reported experienced types of rural road crashes 


\subsubsection{Drivers/riders' self-reported affected body regions during the various experienced crashes}

Figure 3 shows the different body regions and the percentages of drivers/riders' who reported being affected by rural road crashes. More than $72 \%$ (58\% of motor cycle riders and $18 \%$ of motor vehicle drivers) recounted to have been involved in at least one crash or another on the rural roads and sustained injuries. Among this group, $68.8 \%$ reported that the injury kept them away from their normal work for several days with some incurred medical bill. Leg injury was mostly reported by $88 \%$. This was followed by arm/hands injury (68\%), knee injury (65\%). Other reported sustained injuries included the head (34\%), hip (25\%) and chest $(23 \%)$ regions.

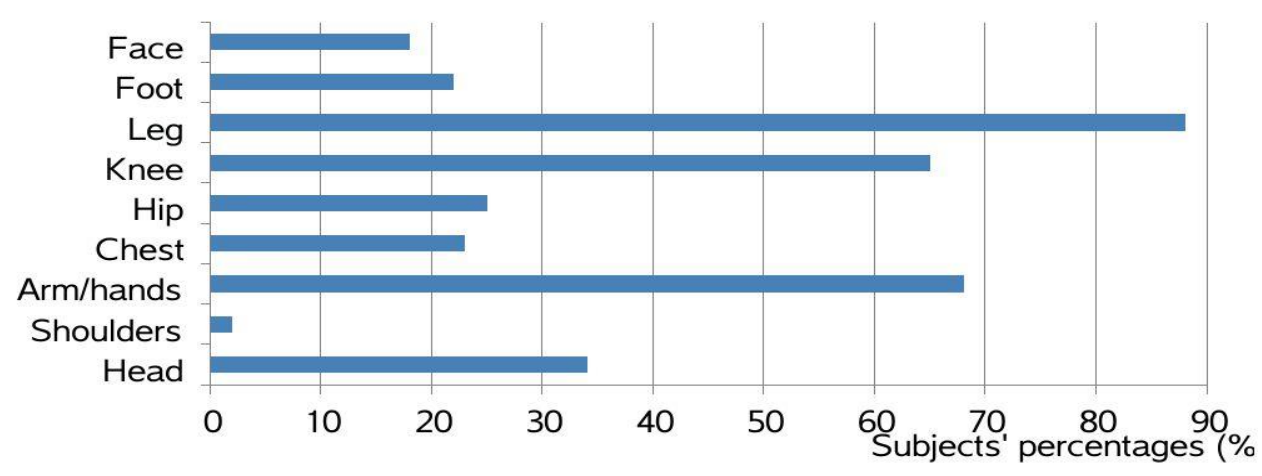

Figure 3: Drivers/riders' reported body regions affected during rural road crashes

\subsubsection{Drivers/riders reported opined risk factors making rural road crashes unavoidable}

Figure 4 demonstrates the various reported essential risk factors opined by the drivers/riders making rural road crashes unavoidable. As reported by the affected subjects, $89 \%$ opined that the poor state of the roads led to the crashes experienced. Rough driving/riding, high speed, lack of safety wears and alcoholic drinks were also mentioned by, $62 \%, 35 \%, 24 \%$, and $15 \%$ respectively of the respondents.

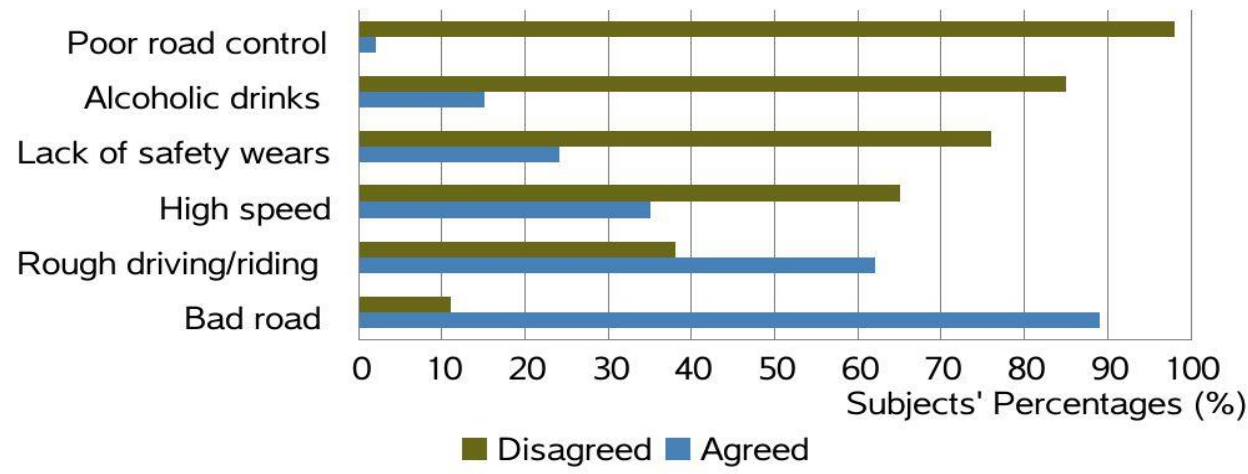

Figure 4: Drivers/riders reported risk factors opined to making the rural road crashes unavoidable

\subsubsection{Drivers/riders reported suggested solutions to minimizing rural road crashes}

Figure 5 displays drivers/riders' suggested solutions to minimizing rural road crashes. In their opinions, $92 \%$ mentioned that the road crashes may continue unavoidably until the roads are properly rehabilitated. $45 \%$ recommended an improvement in relevant training of commercial rural road users as one key solution to reducing the crash just as $25 \%$ suggested enforcement of safety wears. $13 \%$ and $11 \%$ however viewed enhancement of road control by 
relevant government agents and introduction of speed limits on the road respectively as possible solutions to reducing the crashes.

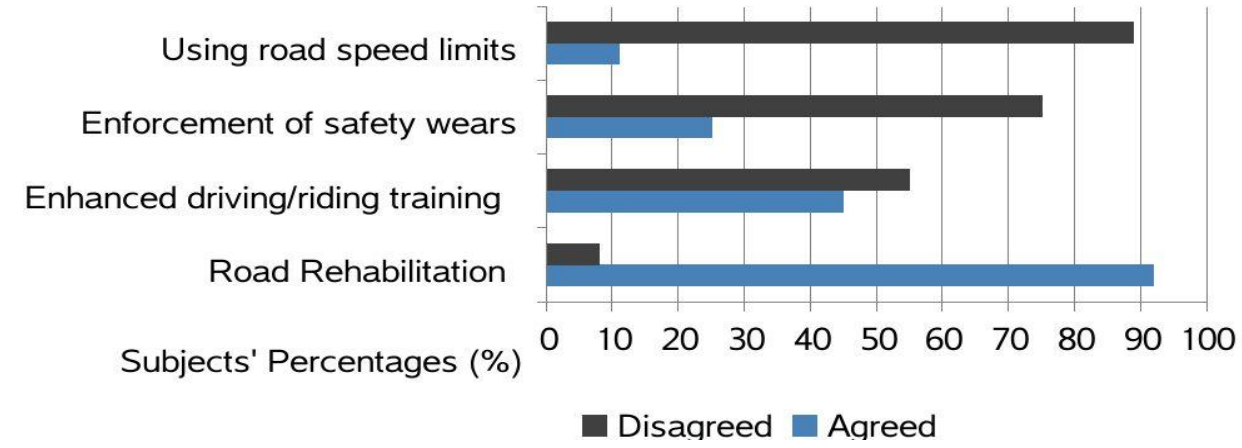

Figure 5: Drivers/riders reported opined solutions to minimizing rural road crashes

\subsection{Moveable rural road maintenance equipment condition's survey}

\subsubsection{Respondents' demographic information and responses to questionnaire}

Table 1 shows the demographic characteristics of the participants in all Local Governments covered in the study. Three hundred and eighty nine (389) out of 430 representing $90.5 \%$ responses were recovered from the questionnaire administered. The majorities in the technical category were of 49years of age and have spent not less than 7 years on current rank in the LG service. Among the SFOs however, the majority were 46 years of age with at least 6 years' experience on the current job position.

Table 1: Demographic information of respondents in all LGs studied

\begin{tabular}{lll}
\hline Descriptions & Age & $\begin{array}{l}\text { Years of working } \\
\text { experience on current rank }\end{array}$ \\
\hline Mean & $51.0^{*}(45)^{*}$ & $6.4^{*}(5)^{*}$ \\
Mode & $49.0^{*}(46)^{*}$ & $7.5^{*}(6)^{*}$ \\
Std. Deviation & $3.8^{*}(5.8)^{*}$ & $3.2^{*}(2.6)^{*}$ \\
\hline
\end{tabular}

\subsubsection{Conditions of the moveable rural road maintenance equipment sighted and counted}

Table 2 is an account of the observed conditions of moveable rural road maintenance equipment in all the LGs studied. The table contains the total number (137) of LG in the Southwest States of Nigeria out of which 84 representing $61.5 \%$ were studied. Through observation method, the number of functional and non-functional machinery and vehicles sighted and counted were listed.

Table 2: Conditions of moveable rural road maintenance equipment

\begin{tabular}{|c|c|c|c|c|c|c|}
\hline $\begin{array}{l}\text { States in } \\
\text { SW } \\
\text { Nigeria }\end{array}$ & $\begin{array}{l}\text { Total } \\
\text { L.G }\end{array}$ & $\begin{array}{l}\text { L.G } \\
\text { studied }\end{array}$ & $\begin{array}{l}\text { Functional } \\
\text { Road } \\
\text { Machinery }\end{array}$ & $\begin{array}{l}\text { Non- } \\
\text { Functional } \\
\text { Machinery }\end{array}$ & $\begin{array}{l}\text { Functional } \\
\text { Vehicles }\end{array}$ & $\begin{array}{l}\text { Non- } \\
\text { Functional } \\
\text { Vehicles }\end{array}$ \\
\hline Ogun & $\begin{array}{l}20 \\
16\end{array}$ & $\begin{array}{l}14 \\
12\end{array}$ & 16 & 50 & 11 & 23 \\
\hline Ekiti & & & 12 & 45 & 8 & 17 \\
\hline Lagos & 20 & 12 & 15 & 18 & 17 & 14 \\
\hline Ondo & 18 & 10 & 7 & 40 & 10 & 13 \\
\hline Osun & 28 & 18 & 14 & 47 & 16 & 20 \\
\hline Oyo & 35 & 18 & 18 & 33 & 17 & 33 \\
\hline Total & 137 & 84 & 82 & 233 & 79 & 120 \\
\hline
\end{tabular}


The number of machinery functional and available for road maintenance works in all the LGs covered was 82 representing $26 \%$ of the total machinery (137) counted. Those awaiting repairs were 233 which was about $74 \%$ of the total. The total number of vehicle dedicated for road maintenance monitoring was $79(39.6 \%)$ of the total vehicles evaluated. Those vehicles grounded and awaiting corrective maintenance were about 120 , representing $60 \%$ of the total vehicles.

\subsubsection{STO and SFO reported maintenance policies implemented by LGs to enhance operations of MRRME}

Figure 6 and 7 describe the responses of STOs and SFOs to the levels of LGs planning for maintenance and structuring of frameworks for operating maintenance program. About $90.2 \%$ of the responses stated that there were no plans put in place for short or long range maintenance of MRRME. 88.4\% mentioned that there were no funds specifically dedicated for renewing MRRME components to improve their conditions. About $14.4 \%$ of the total responses reported low improvement of MRRME conditions in their LG, whereas about $85.6 \%$ stated that no improvement was visible as most of the moving equipment were either underserviced or grounded. Though about $76 \%$ response supported that a particular department was saddled with the responsibility of coordinating maintenance work, however $81 \%$ of the group reported that no maintenance aids was provided to be used for their duties and that maintenances of equipment were only carried out.

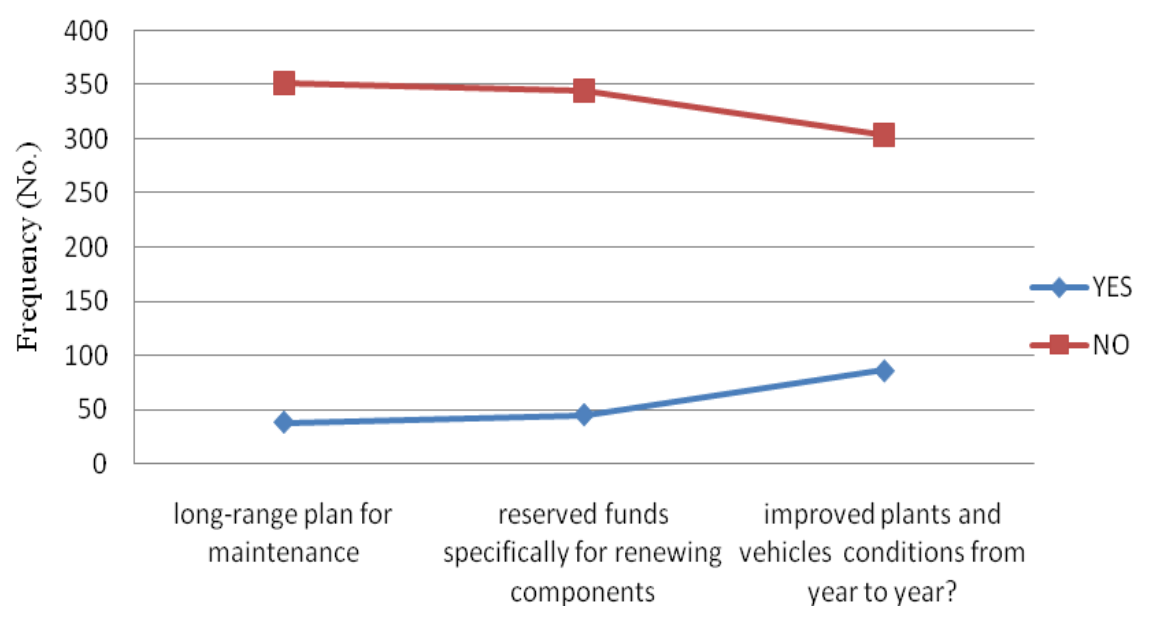

Figure 6: STO and SFO responses to planning for maintenance in the long- and short-term

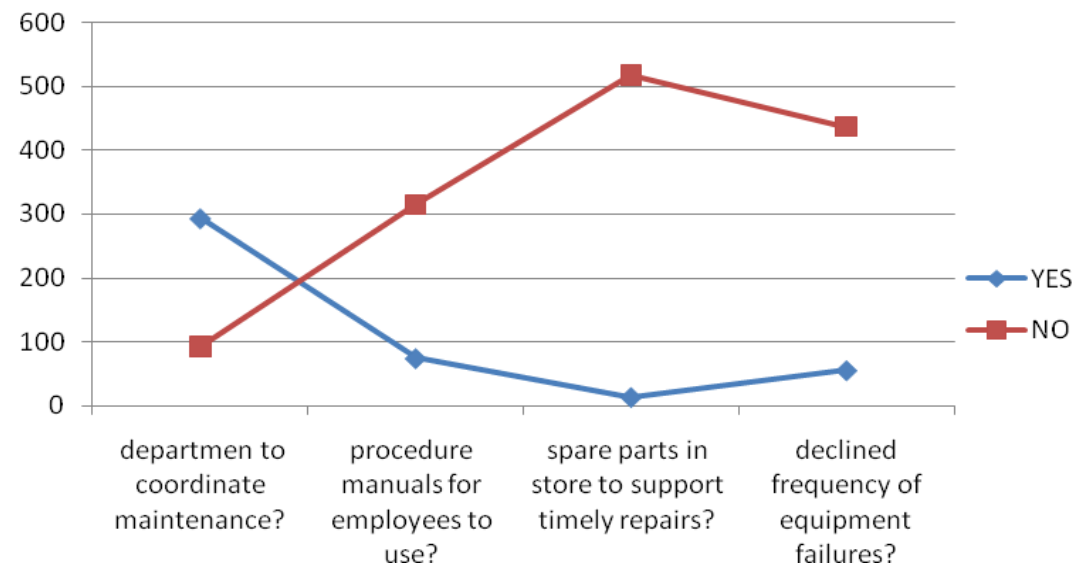

Figure 7: STO and SFO responses to structuring a framework for operating maintenance program 


\subsection{Statistic tests}

\subsubsection{The independent-samples $t$-test}

The independent-samples t-test appraised whether the mean of the scores of the employers' MPM policy rated by STO are significantly different from that reported by SFO. The result found STO's mean mark (mean $=.5956$, SEM $=.05344$ ) significantly lower in numerical value compared to that reported by the SFO (mean=.6668, SEM=.04263), with $\mathrm{t}(428)=-5.146, \mathrm{p}=$ 0.421 . The "Sig. (2-tailed)" value was greater than 0.05 , hence the groups' means ratings are significantly not different. The result indicated that the MPM program rated low (by STOs ( 0.60 meaning poorly performed) and SFOs ( 0.67 meaning poorly performed) by the STO were also confirmed same by the SFO showing that the LGs managements performed very poorly at MPM policy implementations.

\subsubsection{One-way ANOVA analysis}

The one-way analysis of variance determine whether there was any statistically significant differences between the means of responses of road user (external remarks from commercial motorcycle riders and motor vehicle drivers) and the employees of LGs (internal remarks from STOs and SFOs) to rural road safety related approach of the LGs managements. The ANOVA output, $F(2,677)=9.455, p<.05$, generated the value of $F$ ratio as 9.455 and is significant ( $p$ $=.001$ ) at the .05 alpha level. The 9.455 as the obtained $F$ ratio, and the $\mathrm{p}<.05$ as the probability of obtaining that $\mathrm{F}$ ratio by chance alone, shows there is significant difference between the answers of the three groups of respondents to questions related to whether LGs managements are proactive in their efforts at enhancing rural roads safety for users. A post hoc test however shows the specific pairs of means that are significantly different

\subsubsection{Post Hoc Tests for Multiple Comparisons}

Table 4 is a Post Hoc tests for multiple comparisons between STOs, SFOs and road users' responses to the LGs managements' efforts put in place to enhance rural road safety. The Tukey HSDa test reveals that the Drivers/Riders group $(\mathrm{M}=.8912)$ is significantly different from the STOs group $(\mathrm{M}=.5956)$ and SFOs group $(\mathrm{M}=.6668)$, with a mean difference of -.2656 and .2244 respectively and a $\mathrm{p}$ value of .001 on each case. However the STOs group $(\mathrm{M}=.5956)$ is significantly not different from the SFOs group $(\mathrm{M}=.6668)$, with a mean difference of .0712 and a $\mathrm{p}$ value of .421 .

Table 4: Post Hoc tests for multiple comparisons

\begin{tabular}{|c|c|c|c|c|}
\hline \multicolumn{2}{|c|}{ Factors } & \multirow[b]{2}{*}{$\mathbf{N}$} & \multicolumn{2}{|c|}{$\begin{array}{l}\text { Subset for alpha = } \\
0.05\end{array}$} \\
\hline & & & 1 & 2 \\
\hline \multirow{4}{*}{ Tukey HSD ${ }^{\mathrm{a}}$} & STOs & 183 & .5956 & \\
\hline & SFOs & 247 & .6668 & \multirow[b]{2}{*}{.8912} \\
\hline & Drivers/Riders & 250 & & \\
\hline & Sig. & & .421 & 1.000 \\
\hline
\end{tabular}

As noted in the study, motor-cycle services dominated the rural roads with few commercial motor vehicles plying the roads. Most passengers opted for commercial motorcycle as a means of transportation and this, as reported by Paul [28], may be because motorcycles are timely; sometimes they are able to travel more quickly than conventional vehicles on poor roads. Among the frequently reported crashes on the studied roads, two types were common; lone motorcycle and motorcycle-motorcycle. The majority of motor cycle riders affected by the road crashes reported at least one level of sustained injury. The accidents kept many of them away from their normal works for several days with leg, arm/hands and knee regions of their body 
parts commonly affected.

In their opinions, majority of the riders/drivers opined that poor states of the roads may have lead to reckless driving/ridding, and the crashes, noted with the two categories of the road users. As earlier reported by other authors, the major factors influencing the rate of commercial motorcycle accidents are over speeding and bad roads [29]. These are also parts of the leading causes of motor vehicle crashes. As the road users try to manoeuver so as to avoid potholes, they may lose control and skid off their tracks. This may result into a lone motorcycle crash and/or colluding with other road users. Whichever the type, road accidents cause physical and emotional pains to riders and/or passengers. Sometimes they are fatal because riders often carried three or more passengers at a time.

The commercial road users which participated in the study, opined that crashes may continue unavoidably until the roads are properly rehabilitated and/or drivers/riders undergo some enhanced road traffic safety trainings. This submission agreed with the view of many authors such as Ogwueleka and Ogwueleka [30] who spotted road conditions among the major factors leading to road crashes. As observed in the extended study to Local Governments, only $26 \%$ of all moveable rural road maintenance equipment were sighted and counted functional. Some were abandoned for many years and the effects of weather elements like bubble paint, crack, chip or peel, were visible on their exterior panels causing premature ageing of the equipment. Some of the LGs had no dedicated vehicle(s) for road infrastructure monitoring and maintenance. The numbers of non-functional MRRME counted were more than those observed to be in good conditions. This may have greatly influenced the low degree of availability of the equipment for road infrastructure maintenance.

Majority of the LGs had no designated store, no staff in charge of disbursement of spare parts and there were no trace of spare parts in stock. On equipment maintenance needs of any of the functional MRRME, requisition for procurement of needed components were processed by the relevant departments but in most of such cases, the requests were poorly attended to, leading to abandonment of most of the equipment. This is one of the major reasons why non-functional road machinery sighted and counted outnumbered the functional ones. The downtimes of the equipment reduced their availability for road maintenance works. It was evidence that there were little or no plans for short and long term preventive maintenance of the MRRME and no budgeted fund for components renewal. Corrective maintenance method was common to all the LGs.

Findings were clear indications that maintenance performance measures policy implementation in the study domains were poor. The two categories of senior officers (technical and financial) included in the survey, as confirmed by statistical t-test, agreed to low rating for maintenance performance measures of the LGs. The STOs who were directly involved in management of MRRME scored employers below 1.0 (.5956). In a similar manner, the SFOs who were responsible for disbursement of funds also rated the same employers below 1.0 (.6668). Though SFOs mean rating was .0712 points higher than STOs' mean score, the linguistic interpretation of the two ratings is the same; the LGs managements performed poorly in MPM policy implementations.

When responses from internal sources (LGs'STOs and SFOs) were compared with the external remarks (rural roads' users) on the attitudes of Local Government managements to safety on rural roads (maintenance performance measures), statistical test was significant. There were differences in the answers provided by the two groups. While an average of 0.6312 values was allocated by the internal sources' group responses that of the external group was 0.8912. Although the linguistic interpretation of LGs performances' ratings by these two groups is 'poorly performed', the rural road users allocated extra 0.26 marks to the administrators of LGs above which some of their senior employees rated them.

It was clear that the safety approach of LGs administrators at managing the MRRME for the rural roads sustenance was weak. The personnel attached to the operations of the equipment were available but, as consequence, some of the personnel were idle because of the downtimes of the equipment. The costs of equipment failures with the total overhead cost of 
idle personnel were not reducing either. Although some technical workers reported participation in trainings once a year but that some of the trainings lacked information on management of improved technological based machinery, making it difficult to maintain some of the facilities.

The one approach qualitative design used in this study involved in-depth focus groups interviews which were served to obtain information useful to contribute towards the development of a safety attitude scale of Local government management. The subjects involved were representative samples of the wider population and the generalizations are expected well. Inferences were made from the study about these larger groups, the representative sample of the wider population of people using the road infrastructures. The implementation of rural road traffic safety based on the results obtained will help to reverse the reports, in no distance time, that ranked Nigeria as the second-highest in the rate of road accidents among 193 countries of the world [31] and the World Health Organization [32] which adjudged the country as the most dangerous in Africa with 33.7 road accident deaths per 100,000 populations every year. The road users need attitudinal change at emphasizing road traffic safety with good general conducts in driving/riding on Nigeria roads in general. With the present conditions of the roads, recklessness should be reduced if not completely eliminated. Passengers' loading should be done with safety in focus. On management parts, not all the factors leading to equipment breakdowns incidents were beyond control of the LGs managements and not in all cases would there be no resources to implement maintenance. There is the need for establishment of consistent and adequate measures on the part of managements at placing values on infrastructures upkeep. The managerial strong will to ensure that the road maintenance equipment continues to perform is required and should be highly prioritized.

\section{CONCLUSIONS}

This study, surveyed the rate of rural road crashes and the effects among commercial drivers/riders, carried out maintenance performance measures on moveable rural road maintenance equipment (MRRME) available for road repairs in the Local Governments of Southwest Nigeria. It can be concluded from the study that more than $72 \%$ of the commercial drivers/riders on the roads reported involvements in at least one crash or another and also sustained injuries. Leg injury was mostly reported followed by arm/hands and knee injuries. Majority opined that the poor state of the roads may have lead to the reported crashes and that the road accidents may continue unavoidably until the roads are properly rehabilitated

The MRRME at the Local Governments system was noted as being awfully maintained with less than $26 \%$ devoted for rural road maintenance. There was virtually no measure put in place for preventive maintenance of the equipment. This contributed to high level of failures and total neglects of useful equipment for road maintenance and also lead to rural roads deterioration. The authors suggested attitudinal changes on the side of the drivers/riders to emphasize safety in driving/riding, passengers loading and general conducts. The LGs will also need to wake up to their responsibilities at providing better managerial policies for adoption of proper maintenance techniques for MRRME. These measures among others, will help to enhance efforts to properly manage the roads and reduce accidents' death counts in Nigeria rural roads

\section{REFERENCES}

[1] Peden, M.M, McGee, K, Krug, E. (2002). Injuries WHO, Dept VP. Injury: a leading cause of the global burden of disease, 2000: Dept. of Injuries and Violence Prevention, Noncommunicable Diseases and Mental Health Cluster, WHO;

[2] Peden M.K, Krug, E. (2000). Injury: a leading cause of the global burden of disease, 2000. Geneva: WHO; 2002. The injury chart book.

[3] Austroads, 1994. Road Safety Audit. Sydney

[4] Hilling, D. (1996) Transport and Developing Countries. Routledge. London. IFAD (2001) 
Assessment of Rural Poverty in Western and Central Africa. Project Management Department, International Fund for Agricultural Development (IFAD) Western and Central Africa Division, Project Management Department. Palombi. Rome. Available at http://www.ifad. org. Accessed on $14 / 8 / 10$

[5] Mohan D. (2002). Road safety in less-motorized environments: future concerns. International Journal of Epidemiology; 31:527-32.

[6] Lateef F. Riding Motorcycles: is it a lowerlimb hazard? SMJ. 2002; 43(11):566-9.

[7] Bryson M.( 2012) Motorcycle Crash: Injuries Pattern And Associated Factors Among Patients Treated At Muhimbili Orthopaedic Institute. A Published Dissertation For The Degree Of Master Of Medicine Of Muhimbili University Of Health And Allied Sciences Muhimbili University Of Health And Allied Sciences

[8] Akinola, S. R. (2007) "Coping with Infrastructural Deprivation through Collective Action among Rural People in Nigeria". Nordic Journal of African Studies. (16) 1:30-46.

[9] Igomu T (2011), Year major highways collapsed into death traps. Daily sun newspaper Thursday 29th December 2011, page 34.

[10] Okigbo N. (2012), Causes of highway failures in Nigeria. International journal of engineering science and technology (IJEST), Vol.4(11), pp 4695-4703

[11] Federal Ministry of Works (2013), Compendium Report on Road Infrastructure and Related Development in Nigeria- An investor's Manual Available from www.works.gov.ng retrieved December 2017.

[12] Aderamo J. and Magaji, S. A. (2010). "Rural Transportation and the Distribution of Public Facilities inNigeria: A Case of Edu Local Government Area of Kwara State”. Journal of Human Ecology, 29(3) pp. 171-179.

[13] Oguara T. M. (2010), A management model for road infrastructure maintenance. Book of proceedings, 19th engineering assembly,

[14] Abdulkadir, B.U. (2014). Analysis of condition of rural road transport in kwara state, Nigeria European Scientific Journal February edition Vol.10(5) pp 288-307.

[15] British Standard Glossary (BSG). (1993). Maintenance Definition. Available:www.faculty.ksu.edu.sa Retrieved January 2014.

[16] Iwarere H.T. and Lawal K.O. (2011). "Performance Measures of Maintenance of Public Facilities in Nigeria”. Research Journal of Business Management. Vol. 5 pp. 16-20.

[17] Edwards, D. Holt G.and Harrism, F. Maintenance In Maintenance management of heavy duty construction plant and equipment, Chandos Publishing. Oxford Limited, England, 1998.

[18] Robert C. M. (2000). The Role of Career Development in Improving Organizational Effectiveness and Employee Development. [Online]. Available: http://sks.karabuk.edu.tr/kariyer/belgeler. Retrieved August 2014

[19] Adedokun M. O. (2011). "Education for maintenance culture in Nigeria: Implications for community development". International Journal of Sociology and Anthropology. Vol. 3(8), pp. 290294.

[20] Abdulkareem, Y. A. and Adeoti, K.A. (2004). "Road Maintenance and National Development". National Engineering Conference, Federal Polytechnic, Offa. Available: Kwara State.nttps://www.unilorin.edu.ng.

[21] Achimugu, H. Stephen, M. Roberts, A. Uyo, J. (2013). Local Government Service Delivery in Nigeria: An Empirical Comparison of Government Efforts and the People's Expectations, Mediterranean Journal of Social Sciences, Vol 4 ( 6), pp 311-327.

[22] Alexander, M.; Nikolai, V.; Sergey, K.; Yuri, C.; Julia, L. (2009). Maintenance of rolling stock serviceable condition as the factor for providing of traffic regularity. Proceedings of the 9th International Conference .Re liability and Statistics in Transportation and Communication Riga, Latvia,p.10-14. Avalable: www.tsi.lv.

[23] Steven, M. B. (2011). A Checklist for Measuring Performance. [Online]. Available: http://www.auditor.leg.state.mn.us/Ped/pedrep/0006b.pdf. 2011. Retrieved August 2014.

[24] Jody, H. (2000). Checklist for Measuring Performance [Online].Available: http://www.auditor.leg.state.mn.us/... Retrieved June 2012.

[25] Numrah, S. (2012). Pnline]. Available:http://www.scribd.com/doc/82914385. Retrieved March 2014.

[26] Minnesota Department of Transportation (MDT), Annual Transportation Performance Report 2010. [Online]. Available:www.dot.state.mn.us.2011.Retrieved July 2013.

[27] Matthew, R., 2004. Advanced Research Methods in Psychology. Available online at: 
www.psychologyaustralia.homestead.com, Accessed on 12 September 2013

[28] Paul S (2016): The benefits and challenges of increasing motorcycle use for rural areas International Conference on Transportation and Road Research, Mombasa, 15-17 March 2016

[29] Meuleners, L.S:, Lee, A.H. and Harworth, C. (2007). Road Environment, crash type and hospitalization of bicyclists and motorcyclists presented to emergency departments in Western Australia. Accident Analysis and prevention 39: 1222 - 1225. Retrieved 18th March, 2011 from www.hinari.com.

[30] Ogwueleka, F. N. and Ogwueleka, T. C. (2012) Traffic Accident Data Profiling and Clusteringwith Data Mining Process Journal of Computer Engineering Volume 6(2), PP 14-22

[31] Agbonkhese, O, Yisa, G.L, Agbonkhese, E.G, Akanbi, D.O, Aka, E.O, Mondigha, E.B (2013), Road Traffic Accidents in Nigeria: Causes and Preventive Measures. Civil and Environmental Research, Vol.3 (13), pp 90-99.

[32] World Health Organisation (2013). Global status report on road safety 2013. Available from http://www.who.int/violence_injury_prevention/road_safety_status/2013 retrieved December 2016. 